\title{
KAJIAN OBJEK WISATA SEJARAH BERDASARKAN KELAYAKAN LANSKAP SEJARAH DI KOTA PALEMBANG
}

\author{
Myrna Sukmaratri \\ Program Studi Perencanaan Wilayah dan Kota Universitas Indo Global Mandiri Palembang \\ Penulis Korespondensi email : myrnasukma@uigm.ac.id
}

\begin{abstract}
As a city incorporated within the Jaringan Kota Pusaka Indonesia (JKPI), Palembang City certainly has the potential of historical and cultural assets that can be utilized as a tourist attraction. However, tourists who visit the historical attractions in Palembang is still dominated by domestic tourists and even local tourists. Though the historical tourist attraction actually has the potential to bring in more tourists when balanced with optimal development. The purpose of this study is to analyze the potential of historical attractions based on the feasibility of the historical landscape. Scoring analysis techniques used to evaluate the value of the feasibility historical landscape as a tourist attraction so the potential class is obtained. Scoring results obtained that Kawah Tengkurap and Kampung Kapitan included in the low category. Museum Sultan Mahmud Badaruddin II, Makam Ki Gede Ing Suro, and Kampung Assegaf included in medium category. Meanwhile, the tourist attractions are included in the high category areBenteng Kuto Besak, Kampung Al Munawar, Taman Purbakala Kerjaan Sriwijaya, Bukit Siguntang, Museum Balaputra Dewa, and Jembatan Ampera.
\end{abstract}

Keywords: History Tour, Landscape History, Palembang City

\begin{abstract}
ABSTRAK
Sebagai kota yang tergabung di dalam Jaringan Kota Pusaka Indonesia (JKPI), Kota Palembang tentu memiliki potensi aset sejarah dan budaya yang dapat dimanfaatkan sebagai objek wisata. Namun, wisatawan yang berkunjung pada objek wisata sejarah di Palembang masih didominasi wisatawan nusantara bahkan wisatawan lokal. Padahal objek wisata sejarah tersebut sebenarnya memiliki potensi mendatangkan lebih banyak wisatawan manakala diimbangi dengan pengembangan yang optimal. Tujuan penelitian ini adalah untuk menganalisis potensi objek wisata sejarah berdasarkan kelayakan lanskap sejarah. Teknik analisis skoring digunakan untuk mengevaluasi nilai kelayakan lanskap sejarah sebagai objek wisata sehingga didapatkan klas potensi. Dari hasil skoring didapatkan Kawah Tengkurap dan Kampung Kapitan termasuk dalam kategori rendah. Museum Sultan Mahmud Badaruddin II, Makam Ki Gede Ing Suro, dan Kampung Assegaf termasuk dalam kategori sedang. Sedangkan, objek wisata yang termasuk dalam kategori tinggi yakni Benteng Kuto Besak, Kampung Al Munawar, Taman Purbakala Kerjaan Sriwijaya, Bukit Siguntang, Museum Balaputra Dewa, dan JembatanAmpera.
\end{abstract}

Kata Kunci: Wisata Sejarah, Lanskap Sejarah, Kota Palembang 
Jurnal Planologi Vol. 15, No. 2, Oktober 2018

Available : http://jurnal.unissula.ac.id/index.php/psa

\section{PENDAHULUAN}

Pariwisata merupakan suatu kegiatan atau perjalanan dari satu tempat ketempat lainnya yang bersifat sementara dan dilakukan untuk memanfaatkan waktu luang untuk menghilangkan kejenuhan (Spillane, 1987 dalam Selvia, 2011). Agustina (2011) juga menjelaskan bahwa pariwisata ialah aktivitas seseorang atau sekelompok orang dalam mencari kesenangan dengan menikmati hiburan sehingga dapat mengurangi kelelahan. Berdasarkan dua pengertian pariwisata tersebut, didapatkan fakta bahwa manusia membutukan wisata sebagai objek hiburan yang menjadikan pariwisata dan wisata itu sendiri terus hidup. Terdapat berbagai jenis sektor kepariwisataan salah satunya adalah pariwisata berbasis sejarah.

Pariwisata berbasis sejarah merupakan salah satu potensi yang pada umumnya dimiliki oleh setiap daerah, yang menjadikan daerah tersebut berbeda dengan daerah lainnya bahkan menjadi cirri khas atau karakteristik dari daerah (Suyatmin,2014). Terkait potensi wisata berbasis sejarah tersebut, Kota Palembang yang saat ini telah berusia 1334 tahun merupakan kota tertua di Indonesia (dibangun 17 Juni 683). Dengan rentang usia yang demikian panjang maka Kota Palembang memiliki peninggalan-peninggalan sejarah seperti, kemegahan kerajaan Sriwijaya sebagai kerajaan Hindu terbesar di Indonesia hingga kearifan hasil akulturasi budaya lokal dan Kesultanan Palembang Darussalam. Berbagai peninggalan sejarah inilah yang menjadikan kota Palembang memiliki macam daya tarik wisata sejarah yang potensial.

Selain itu, pada tanggal 25 Oktober 2018 Kota Palembang telah masuk dalam Jaringan Kota Pusaka Indonesia (JKPI) yang berarti bahwa Kota Palembang memiliki kekenatalansejarah yang di dalamnya terdapat pusaka alam dan budaya sebagai aset pusaka yang menjadi bagian kota yang hidup, berkembang dan dikelola secara efektif (Ernawi, 2012). Hal ini didukung oleh pernyataan Goodchild (1990) bahwa berbagai obyek peninggalan sejarah dan lanskap sejarah terutama yang bernilai signifikan, harus dikonservasi karena merupakan fakta fisik dan arkeologi dari warisan sejarah dan budaya yang berkontribusi untukkepentingan ekonomi masyarakat. Karena menurut Spillane (1987 dalam Selvia, 2011) suatu objek budaya juga memberikan peran penting dalam memperkenalkan keragaman budaya seperti kesenian tradisional, uparaca adat, bangunan peninggalan sejarah yang dapat menarik perhatian wisatawan asing maupun lokal.

Namun peninggalan objek budaya sejarah yang ada di Kota Palembang, seperti Jembatan Ampera, Benteng Kuto Besak, dan Museum Sultan Mahmud Badaruddin II 
Belum sepenuhnya dimanfaatkan dan dilestarikan secara optimal. Wisatawan yang berkunjung pun didominasi oleh wisatawan local dan nusantara, padahal peninggalan bersejarah mempunyai daya tarik yang besar yang juga dapat menarik wisatawan mancanegara. Sehingga untuk mengembangkan wisata sejarah Kota Palembang dengan memberdayakan elemen dan lansekap budaya sebagai objek wisata serta nilai-nilai kultural yang terdapat di Kota Palembang, diperlukan sebuah kajian guna menemukan potensi objek wisata sejarah berdasarkan kelayakan lanskap untuk selanjutnya diketahui strategi pengembangan berdasarkan variable kelayakan lanskap yang perlu dioptimalkan guna meningkatkan kesejahteraan kota dan masyarakat.

UNESCO (2009) menyebutkan bahwa Organisasi Wisata Dunia (World Tourism Organization) mendefinisikan pariwisata pusaka sebagai kegiatan untuk menikmati sejarah, alam, peninggalan budaya manusia, kesenian, filosofi dan pranata dari wilayah lain. Sementara, Badan Preservasi Sejarah Nasional Amerika (The National Trust for Historic Preservation) mengartikannya sebagai perjalanan untuk menikmati tempattempat, artefak-artefak dan aktifitas-aktifitas yang secara otentik mewakili cerita/sejarah orang-orang terdahulu maupun saat ini. Sedangkan Spillane (1987 dalam Selvia, 2011) mengungkapkan bahwa pariisata berbasis sejarah merupakan salah satu jenis pariwisata yang dilakukan karena dilatar belakangi keinginan untuk mengetahui atau mempelajari adat istiadat, kelembagaan dan cara hidup masyarakat juga untuk mengunjungi monumen bersejarah, peninggalan masa lalu, pusat kesenian, keagamaan maupun ikut serta dalam kegiaan kesenian rakyat.

Komponen pariwisata ialah komponen yang harus ada dalam pengembangan sebuah pariwisata sehingga tercipta suatu pariwisata yang optimal. Abdur Rajak dan Rimadewi Supihardjo (2013) mengemukakan beberapa komponen pariwisata yang merupakan gabungan dari beberapa teori, yaitu teori Inskeep, Intosh dan Suwantoro. Berikut adalah tabel komponen pariwisata menurut tiga sumber :

Tabel 1. Komponen Pariwisata

\begin{tabular}{|l|l|l|}
\hline \multicolumn{1}{|c|}{ Inskeep (1991) } & \multicolumn{1}{|c|}{ Intosh (1995) } & \multicolumn{1}{c|}{ Suwantoro (1997) } \\
\hline Atraksi dan kegiatan-kegiatan wisata & Sumberdaya alam & ODTW \\
\hline Akomodasi & Infrastruktur & Prasarana Wisata \\
\hline Fasilitas dan pelayanan wisata & Moda Transportasi & SaranaWisata \\
\hline Pelayanan Transportasi & Partisipasi Masyarakat & Tatalaksana/ infrastruktur \\
\cline { 1 - 2 } Infrastruktur lain & Sumberdaya Budaya & Masyarakat \\
\cline { 1 - 1 } Elemen Kelembagaan & & \\
\cline { 1 - 2 } & &
\end{tabular}

Sumber :Abdur Razak dan Rimadwi Supihardjo, 2013 
Adapun manfaat atau keuntungan-keuntungan dalam pengembangan pariwisata pusaka/sejarah (Walker, 1996):

\section{Ekonomi}

- Tersedianya kesempatan kerja;

- Keragaman lapangan pekerjaan;

- Peningkatan pendapatan penduduk maupun daerah;

\section{Fisik}

- Mempertahankan bangunan bersejarah dan pusaka budaya/alam;

- Peningkatan infrastruktur;

- Meningkatnya upaya-upaya konservasi flora/fauna dan ekosistemnya;

\section{Sosial}

- Semakin dikenalnya masyarakat di daerah tujuan wisata;

- Meningkatnya upaya-upaya menjaga nilai-nilai budaya setempat;

- Meningkatnya kebanggaan warga; meningkatnya kesempatan akan pendidikan yang lebih tinggi;

- Membantu warga untuk lebih memahami diri sendiri (siapa mereka, di mana mereka berada serta apa keunikan mereka);

\section{METODOLOGI}

Penelitian dilakukan dalam tiga tahap yaitu tahap inventarisasi pengumpulan data, tahap pengolahan data dan analisis data. Metode pendekatan dalam penelitian ini adalah deskriptif kuantitatif dengan teknik analisis skoring. Metode pengambilan data primer menggunakan observasi dan ditunjang dengan data sekunder berupa dokumen atau kebijakan dari sebuah instansi/ dinas pemerintahan Kota Palembang dan literatur studi kepustakaan dari jurnal, serta hasil studi-studi terdahulu yang memiliki kaitan dengan objek penelitian.

Analisis skoring matrik akan digunakan untuk mengevaluasi nilai kelayakan lanskap sejarah sebagai objek wisata sehingga didapatkan klas potensi dari masing-masing objek wisata. Klas potensi objek wisata dinilai dengan kriteria keaslian lanskap sejarah, daya tarik dari suatu objek wisata, dan aksesibilitas. Secara rinci penilaian masing-masing kategori tersaji pada tabel-tabel berikut. 
Tabel 2. Kriteria Keaslian Lanskap Sejarah

\begin{tabular}{|c|c|c|c|c|}
\hline \multirow[t]{2}{*}{ No } & \multirow{2}{*}{ Kriteria } & \multicolumn{3}{|c|}{ Skor } \\
\hline & & 1 (Rendah) & 3 (Sedang) & 5 (Tinggi) \\
\hline 1 & $\begin{array}{l}\text { Land use } \\
\text { (Penggunaan } \\
\text { lahan) }\end{array}$ & $\begin{array}{l}\text { Mengalami } \\
\text { perubahan lahan } \\
>50 \% \text {. }\end{array}$ & $\begin{array}{l}\text { Mengalami perubahan } \\
\text { lahan } 25-50 \% \text {. }\end{array}$ & $\begin{array}{l}\text { Tidak mengalami } \\
\text { perubahan penggunaan } \\
\text { lahan atau berubah } \\
<25 \% \text {. }\end{array}$ \\
\hline 2 & Bangunan & $\begin{array}{l}\text { Elemen bangunan } \\
\text { mengalami } \\
\text { perubahan struktur } \\
\text { dan elemen. } \\
\text { Tidak mewakili } \\
\text { karakter dan gaya } \\
\text { arsitektur masa lalu. } \\
\text { Terdapat sedikit } \\
\text { bangunan kuno } \\
\text { dengan umur >50 } \\
\text { tahun di sekitar situs. }\end{array}$ & $\begin{array}{l}\text { Elemen bangunan } \\
\text { mengalami asimilasi } \\
\text { struktur dan elemen } \\
\text { namun masih mewakili } \\
\text { karakter dan gaya } \\
\text { arsitektur masa lalu. } \\
\text { Terdapat cukup banyak } \\
\text { bangunan kuno dengan } \\
\text { umur >50 tahun di } \\
\text { sekitar situs. }\end{array}$ & $\begin{array}{l}\text { Elemen bangunan tidak } \\
\text { mengalami perubahan } \\
\text { karakter, struktur, dan } \\
\text { elemen. Sangat mewakili } \\
\text { karakter dan gaya } \\
\text { arsitektur rmasa lalu. } \\
\text { Terdapat banyak } \\
\text { bangunan kuno dengan } \\
\text { umur }>50 \text { tahun disekitar } \\
\text { situs. }\end{array}$ \\
\hline
\end{tabular}

Sumber :Adaptasi dari Harris \& Dinnes dalam Wirawan (2014), dimodifikasi

Tabel 3. Kriteria Daya Tarik Wisata Sejarah

\begin{tabular}{|c|c|c|c|c|}
\hline \multirow[t]{2}{*}{ No } & \multirow[t]{2}{*}{ Kriteria } & \multicolumn{3}{|c|}{ Skor } \\
\hline & & 1 (Rendah) & 3 (Sedang) & 5 (Tinggi) \\
\hline 1 & $\begin{array}{l}\text { Asosiasi } \\
\text { Kesejarahan }\end{array}$ & $\begin{array}{l}\text { Elemen tidak memiliki } \\
\text { hubungan kesejarahan }\end{array}$ & 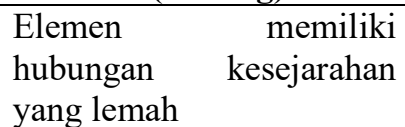 & $\begin{array}{lr}\text { Elemen } & \text { memiliki } \\
\text { hubungan } & \text { kesejarahan } \\
\text { yang kuat }\end{array}$ \\
\hline 2 & Integritas & $\begin{array}{l}\text { Karakter, struktur, dan } \\
\text { fungsi elemen tidak } \\
\text { menyatu dan harmonis } \\
\text { dengan lingkungan } \\
\text { sekitarnya. }\end{array}$ & $\begin{array}{l}\text { Karakter, struktur, dan } \\
\text { fungsi elemen cukup } \\
\text { menyatu dan harmonis } \\
\text { dengan lingkungan } \\
\text { sekitarnya. }\end{array}$ & $\begin{array}{l}\text { Karakter, struktur, dan } \\
\text { fungsi elemen } \\
\text { menyatu dan harmonis } \\
\text { dengan lingkungan } \\
\text { sekitarnya. }\end{array}$ \\
\hline 3 & Kelangkaan & $\begin{array}{l}\text { Karakter dan struktur } \\
\text { elemen bersifat umum } \\
\text { dan dapat dijumpai di } \\
\text { tempat lain dengan } \\
\text { mudah serta tidak } \\
\text { memiliki nilai sejarah. }\end{array}$ & $\begin{array}{lr}\text { Karakter dan struktur } \\
\text { elemen bersifat khas } \\
\text { namun dapat dijumpai di } \\
\text { tempat-tempat tertentu } \\
\text { dan memiliki nilai sejarah. }\end{array}$ & $\begin{array}{l}\text { Karakter dan struktur } \\
\text { elemen bersifat khas } \\
\text { dan jarang dijumpai di } \\
\text { tempat-tempat lain dan } \\
\text { memiliki nilai sejarah. }\end{array}$ \\
\hline 4 & $\begin{array}{l}\text { Kualitas } \\
\text { Estetika }\end{array}$ & $\begin{array}{l}\text { Karakter dan struktur } \\
\text { elemen tidak memiliki } \\
\text { nilai estetika atau gaya } \\
\text { arsitektur yang dapat } \\
\text { menunjukkan } \\
\text { kekhasannya pada masa } \\
\text { lalu. }\end{array}$ & $\begin{array}{l}\text { Karakter dan struktur } \\
\text { elemen masih memiliki } \\
\text { nilai estetika atau gaya } \\
\text { arsitektur yang dapat } \\
\text { menunjukkan } \\
\text { kekhasannya pada masa } \\
\text { lalu. }\end{array}$ & $\begin{array}{l}\text { Karakter dan struktur } \\
\text { elemen memiliki nilai } \\
\text { estetika atau gaya } \\
\text { arsitektur masa lalu } \\
\text { pada hampir semua } \\
\text { bagian, termasuk detail } \\
\text { ornamennya. }\end{array}$ \\
\hline
\end{tabular}

Sumber :Adaptasi dari Harris \&Dinnes dalam Wirawan (2014),dimodifikasi

Tabel 4. Kriteria Kemudahan Aksesibilitas

\begin{tabular}{|l|c|l|l|l|}
\hline No & \multirow{2}{*}{ Kriteria } & \multicolumn{4}{|c|}{ Skor } \\
\cline { 3 - 6 } & & \multicolumn{4}{|c|}{ 1 (Rendah) } & 3 (Sedang) & 5 (Tinggi) \\
\hline 1 & Kemudahan & $\begin{array}{l}\text { Ijin masuk area objek } \\
\text { wisata sulit diperoleh, } \\
\text { objek wisata berada di }\end{array}$ & $\begin{array}{l}\text { Ijin masuk area objek } \\
\text { wisata tidak terlalu sulit, } \\
\text { lokasi objek wisata tidak }\end{array}$ & $\begin{array}{l}\text { Ijin masuk objek wisata } \\
\text { mudah diperoleh, lokasi } \\
\text { tapak objek wisata }\end{array}$ \\
\hline
\end{tabular}




\begin{tabular}{|c|c|c|c|c|}
\hline \multirow[t]{3}{*}{ No } & \multirow{3}{*}{ Kriteria } & \multicolumn{3}{|c|}{ Skor } \\
\hline & & 1 (Rendah) & 3 (Sedang) & 5 (Tinggi) \\
\hline & & $\begin{array}{l}\text { lokasi yang sulit } \\
\text { dijangkau serta beresiko } \\
\text { apabila dikunjungi } \\
\text { banyak orang }\end{array}$ & \begin{tabular}{l}
\multicolumn{3}{c}{ terlalu sulit dijangkau dan } \\
memiliki resiko sedang \\
jika dikunjungi banyak \\
orang
\end{tabular} & $\begin{array}{l}\text { mudah dijangkau dan } \\
\text { resikonya kecil bahkan } \\
\text { tidak ada resiko apabila } \\
\text { dikunjungi banyak orang }\end{array}$ \\
\hline 2 & Kapasitas & $\begin{array}{l}\text { - Lokasi tapak objek } \\
\text { wisata dan jalannya } \\
\text { tidak dapat } \\
\text { menampung } \\
\text { kendaraan. } \\
\text { - Tapak/lokasi hanya } \\
\text { bisa dicapai } \\
\text { pengunjung dengan } \\
\text { berjalan kaki, serta } \\
\text { jumlah pengunjung } \\
\text { yang dapat } \\
\begin{array}{l}\text { ditampung }<100 \\
\text { orang. }\end{array}\end{array}$ & $\begin{array}{l}\text { - Lokasi tapak objek } \\
\text { wisata dan jalannya } \\
\text { dapat menampung } \\
\text { kendaraan kecil } \\
\text { seperti seperti sepeda, } \\
\text { sepeda motor. } \\
\text { - Tapak/lokasi hanya } \\
\text { bisa dicapai } \\
\text { pengunjung dengan } \\
\text { kendaraan kecil serta } \\
\text { jumlah pengunjung } \\
\text { yang dapat ditampung } \\
100-300 \text { orang. }\end{array}$ & $\begin{array}{l}\text { Lokasi tapak objek } \\
\text { wisata dan jalannya dapat } \\
\text { menampung kendaraan } \\
\text { sedang sampai besar, } \\
\text { tersedia lahan parkir yang } \\
\text { memadai untuk jumlah } \\
\text { pengunjung }>300 \text { orang. }\end{array}$ \\
\hline 3 & Kejelasan & 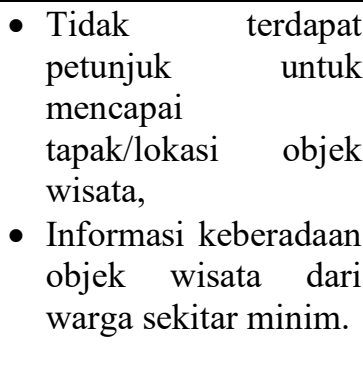 & $\begin{array}{llr}\text { - } & \text { Ada sedikit petunjuk } \\
\text { untuk } & \text { mencapai } \\
\text { tapak/lokasi } & \text { objek } \\
\text { wisata } & \\
\text { - } & \text { beberapa warga sekitar } \\
\text { ada yang mengetahui } \\
\text { keberadaan objek } \\
\text { wisata. }\end{array}$ & 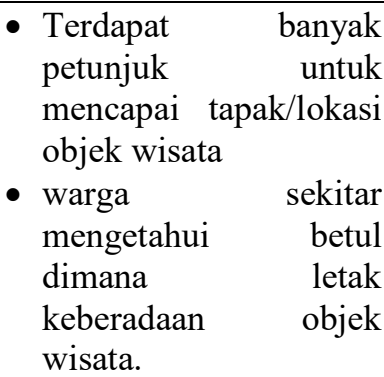 \\
\hline
\end{tabular}

Sumber :Adaptasi dari Harris \& Dinnes dalam Wirawan (2014), dimodifikasi.

Setelah diberi skor, selanjutnya variabel tersebut digolongkan berdasarkan nilai skoring dengan menggunakan interval kelas dengan rumus:

$$
\text { Interval Kelas }(\mathrm{IK})=\frac{\text { Skor maksimum }(\text { Sma })-\text { Skor Minimum }(\text { Smi })}{\text { Jumlah Kategori }}
$$

\section{HASIL DAN PEMBAHASAN}

Evaluasi kelayakan lanskap objek wisata sejarah ini didasarkan dari beberapa variabel, yaitu keaslian lanskap sejarah, daya tarik wisata sejarah, dan kemudahan aksesibilitas. Ketiga variabel ini akan dianalisis dengan analisis skoring. Berikut adalah hasil penilaian kelayakan lanskap sejarah dari masing-masing objek wisata: 
Jurnal Planologi Vol. 15, No. 2, Oktober 2018 Available : http://jurnal.unissula.ac.id/index.php/psa

Tabel 5. Nilai Kelayakan Objek Wisata Sejarah

\begin{tabular}{|c|c|c|c|c|c|c|c|c|c|c|c|c|}
\hline \multirow{3}{*}{ No } & \multirow{3}{*}{$\begin{array}{l}\text { Objek } \\
\text { wisata }\end{array}$} & \multicolumn{9}{|c|}{ Variabel } & \multirow{3}{*}{$\begin{array}{l}\text { Nilai } \\
\text { Total }\end{array}$} & \multirow{3}{*}{ Keterangan } \\
\hline & & \multicolumn{2}{|c|}{$\begin{array}{c}\text { Keaslian lanskap } \\
\text { sejarah }\end{array}$} & \multicolumn{4}{|c|}{ Daya tarik wisata sejarah } & \multicolumn{3}{|c|}{ Kemudahan aksesibilitas } & & \\
\hline & & $\begin{array}{c}\text { Land } \\
\text { use }\end{array}$ & Bangunan & $\begin{array}{c}\text { Asosiasi } \\
\text { Kesejarahan }\end{array}$ & Integritas & Kelangkaan & $\begin{array}{l}\text { Kualitas } \\
\text { Estetika }\end{array}$ & Kemudahan & Kapasitas & Kejelasan & & \\
\hline 1 & $\begin{array}{l}\text { Kampung Al } \\
\text { Munawar }\end{array}$ & 5 & 5 & 5 & 5 & 5 & 5 & 5 & 5 & 5 & 45 & Tinggi \\
\hline 2 & $\begin{array}{l}\text { Kawah } \\
\text { Tengkurap }\end{array}$ & 5 & 3 & 5 & 3 & 5 & 3 & 5 & 3 & 3 & 35 & Rendah \\
\hline 3 & $\begin{array}{l}\text { Benteng } \\
\text { Kuto Besak }\end{array}$ & 3 & 5 & 5 & 5 & 5 & 5 & 5 & 5 & 5 & 43 & Tinggi \\
\hline 4 & $\begin{array}{l}\text { Museum } \\
\text { Sultan } \\
\text { Mahmud } \\
\text { Badaruddin } \\
\text { II }\end{array}$ & 5 & 5 & 5 & 3 & 5 & 5 & 5 & 3 & 5 & 41 & Sedang \\
\hline 5 & $\begin{array}{lr}\text { Makam } & \mathrm{Ki} \\
\text { Gede } & \text { Ing } \\
\text { Suro } & \end{array}$ & 5 & 5 & 5 & 3 & 5 & 3 & 5 & 5 & 3 & 39 & Sedang \\
\hline 6 & $\begin{array}{l}\text { Taman } \\
\text { Purbakala } \\
\text { Kerajaan } \\
\text { Sriwijaya }\end{array}$ & 5 & 5 & 5 & 3 & 5 & 5 & 5 & 5 & 5 & 43 & Tinggi \\
\hline 7 & $\begin{array}{l}\text { Kampung } \\
\text { Assegaf }\end{array}$ & 5 & 3 & 5 & 5 & 5 & 3 & 5 & 5 & 5 & 41 & Sedang \\
\hline 8 & $\begin{array}{l}\text { Masjid } \\
\text { Agung } \\
\text { Sultan } \\
\text { Mahmud } \\
\text { Badaruddin } \\
\text { II }\end{array}$ & 5 & 5 & 5 & 5 & 5 & 5 & 5 & 5 & 5 & 45 & Tinggi \\
\hline 9 & $\begin{array}{l}\text { Monumen } \\
\text { Perjuangan } \\
\text { Rakyat } \\
\text { (Monpera) } \\
\end{array}$ & 5 & 5 & 5 & 5 & 5 & 5 & 5 & 3 & 5 & 43 & Tinggi \\
\hline 10 & $\begin{array}{l}\text { Kampung } \\
\text { Kapitan }\end{array}$ & 3 & 3 & 5 & 3 & 5 & 5 & 5 & 3 & 3 & 35 & Rendah \\
\hline
\end{tabular}


Jurnal Planologi Vol. 15, No. 2, Oktober 2018

Available : http://jurnal.unissula.ac.id/index.php/psa

\begin{tabular}{|c|c|c|c|c|c|c|c|c|c|c|c|c|}
\hline \multirow{3}{*}{ No } & \multirow{3}{*}{$\begin{array}{l}\text { Objek } \\
\text { wisata }\end{array}$} & \multicolumn{9}{|c|}{ Variabel } & \multirow{3}{*}{$\begin{array}{l}\text { Nilai } \\
\text { Total }\end{array}$} & \multirow{3}{*}{ Keterangan } \\
\hline & & \multicolumn{2}{|c|}{$\begin{array}{c}\text { Keaslian lanskap } \\
\text { sejarah }\end{array}$} & \multicolumn{4}{|c|}{ Daya tarik wisata sejarah } & \multicolumn{3}{|c|}{ Kemudahan aksesibilitas } & & \\
\hline & & $\begin{array}{c}\text { Land } \\
\text { use }\end{array}$ & Bangunan & $\begin{array}{c}\text { Asosiasi } \\
\text { Kesejarahan }\end{array}$ & Integritas & Kelangkaan & $\begin{array}{l}\text { Kualitas } \\
\text { Estetika }\end{array}$ & Kemudahan & Kapasitas & Kejelasan & & \\
\hline 11 & $\begin{array}{l}\text { Bukit } \\
\text { Siguntang }\end{array}$ & 5 & 3 & 5 & 5 & 5 & 5 & 5 & 5 & 5 & 43 & Tinggi \\
\hline 12 & $\begin{array}{l}\text { Museum } \\
\text { Balaputra } \\
\text { Dewa }\end{array}$ & 5 & 5 & 5 & 5 & 5 & 5 & 5 & 5 & 5 & 45 & Tinggi \\
\hline 13 & $\begin{array}{l}\text { Jembatan } \\
\text { Ampera }\end{array}$ & 5 & 3 & 5 & 5 & 5 & 5 & 5 & 5 & 5 & 43 & Tinggi \\
\hline
\end{tabular}

Sumber :Hasil Analisis, 2018 
Tabel 6. Hasil Evaluasi Nilai Kelayakan

\begin{tabular}{|c|c|c|}
\hline No & Kategori & Objek Wisata Sejarah \\
\hline 1 & Rendah & $\begin{array}{ll} & \text { Kawah Tengkurap } \\
\text { - } & \text { Kampung Kapitan } \\
\end{array}$ \\
\hline 2 & Sedang & $\begin{array}{ll}\text { - } & \text { Museum Sultan Mahmud Badaruddin II } \\
\text { - } & \text { Makam Ki Gede Ing Suro } \\
\text { - } & \text { Kampung Assegaf } \\
\end{array}$ \\
\hline 3 & Tinggi & $\begin{array}{ll}\text { - } & \text { Benteng Kuto Besak } \\
\text { - } & \text { Kampung Al Munawar } \\
\text { - } & \text { Taman Purbakala Kerajaan Sriwijaya } \\
\text { - } & \text { Bukit Siguntang } \\
\text { - } & \text { Museum Balaputra Dewa } \\
\text { - } & \text { Jembatan Ampera } \\
\text { - } & \text { Monumen Perjuangan Rakyat (Monpera) }\end{array}$ \\
\hline
\end{tabular}

Sumber :Hasil Analisis, 2018

Dari hasil scoring didapatkan tabel 5 dimana objek wisata yang termasuk dalam kategori rendah adalah Kawah Tengkurap dan Kampung Kapitan. Sedangkan, objek wisata sejarah yang termasuk dalam kategori tinggi yakni Benteng Kuto Besak, Kampung Al Munawar, Taman Purbakala Kerjaan Sriwijaya, Bukit Siguntang, Museum Balaputra Dewa, dan Jembatan Ampera. Objek dengan nilai kelayakan lanskap sejarah sebagai objek wisata yang tinggi dapat dijadikan sebagai objek wisata utama dalam menarik minat pengunjung. Sedangkan objek yang memiliki nilai signifikasi sedang dan rendah dapat lebih dioptimalkan dalam pengembangan objek wisata dengan menambah fasilitas wisata dan peningkatan aksesibilitas.

Berikut adalah penjabaran dari masing-masing variabel kelayakan objek wisata sejarah:

\section{A. Keaslian Lanskap Sejarah}

Keaslian lanskap sejarah ini terdiri dari dua kriteria yakni penggunaan lahan dan juga bentuk bangunan. Kriteria penggunaan lahan dilihat dari seberapa besar perubahan penggunaan lahan di objek wisata sejarah tersebut, sedangkan kriteria bentuk bangunan dilihat dari seberapa besar elemen bangunan di objek wisata mengalami perubahan struktur, elemen serta karakter dan gaya arsitektur di masa lampau.

Pada kriteria penggunaan lahan (land use), hampir seluruh objek wisata mendapatkan nilai tinggi. Hal ini dikarenakan penggunaan lahan di objek wisata tidak mengalami perubahan yang signifikan atau hanya $<25 \%$ dari total luasan lahan. Penggunaan lahan di objek wisata sejarah di Kota Palembang tidak banyak berubah atau alih fungsi. Keberadaanya yang memiliki cerita sejarah Kota Palembang masa lampau menjadi faktor utama dipertahankannya oleh Pemerintah Kota Palembang. Pada tahun 
2014, Pemerintah Provinsi Sumatera Selatan telah menggagas pendirian Pusat Informasi Kerajaan Sriwijaya yang diiringi dengan ekskavasi situs dan penelitian mengenai Kerajaan Sriwijaya. Hal ini dilakukan menyusul banyaknya situs penting Kerajaan Sriwijaya di Kota Palembang yang telah beralih fungsi menjadi permukiman. Balai Arkeologi Palembang mencatat sejumlah alih fungsi lahan pada situs Sriwijaya. Beberapa di antaranya adalah Situs Sarangwati di kawasan Lemabang dan Situs Air Bersih di sekitar Pelabuhan Boom Baru. Saat ini, lokasi situs Sarangwati merupakan kawasan permukiman dan di tempat itu tak terlihat lagi tanda-tanda bahwa pernah ada temuan peninggalan Kerajaan Sriwijaya. Situs Sarangwati diduga merupakan tempat peribadatan pada masa Kerajaan Sriwijaya. Dalam sejumlah ekskavasi di Situs Sarangwati pernah ditemukan stupa-stupa kecil dari tanah liat (stupika) dan arca Buddha Avalakitecvara yang diduga belum selesai dibuat. Arca temuan kini disimpan di Museum Sultan Mahmud Badaruddin II. Adapun di Situs Air Bersih pernah ditemukan pecahan keramik dari masa Dinasti Ming dan Sung sertaarcaperungguberlanggamabad IX-X

Untuk criteria bangunan, beberapa objek wisata seperti Jembatan Ampera, Kawah Tengkurap, Benteng Kuto Besak mendapatkan skor sedang karena bangunan di objek wisata tersebut telah mengalami asimilasi struktur namun dianggap masih mewakili karakter dan gaya arsitektur masa lalu. Sebagai contoh, pada tahun 1981, Jembatan Ampera direnovasi setelah muncul kekhawatiran akan jembatan dapat ambruk akibat kerusakan di Jembatan Ampera. Pada tahun 1990, kedua bandul pemberat di menara Jembatan Ampera diturunkan. Contoh lain pada Kampung Kapitan, saat ini sudah banyak rumah-rumah dan bangunan yang telah mengalami renovasi. Awalnya Kampung Kapitan ini permukiman yang terdiri atas beberapa bangunan Namun sekarang yang tersisa hanya dua bangunan rumah berbentuk rumah panggung yang dipadukan dengan gaya kolonial. Selain itu, objek wisata lain mendapatkan skor 3 (sedang) karena meskipun elemen bangunan tidak mengalami perubahan karakter, struktur, dan elemen, namun tidak terlalu banyak bangunan kuno dengan umur $>50$ tahun di sekitar objek wisata. 

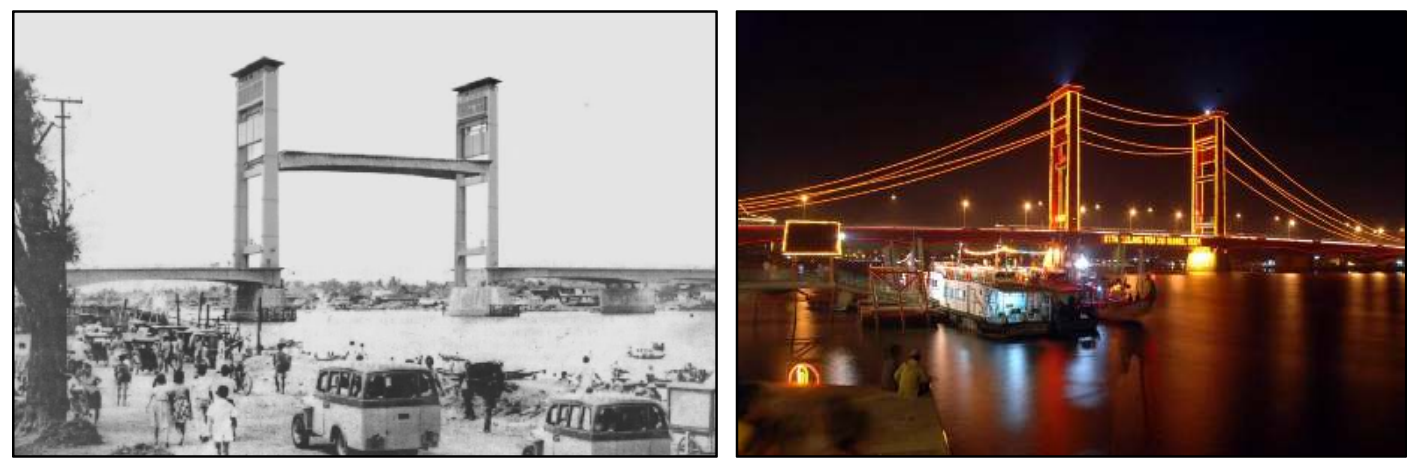

Gambar 1. JembatanAmperaDuludanKini

Sumber :Son Sakira, 2013

\section{B. Daya Tarik Wisata Sejarah}

Menurut Undang-undang Nomor 10 Tahun 2009 tentang Kepariwisataan, daya tarik wisata adalah segala sesuatu yang memiliki keunikan, nilai, dan kemudahan berupa keanekaragaman alam, budaya, dan hasil buatan manusia yang menjadi kunjungan wisatawan. Daya tarik wisata sejarah diukur berdasarkan kriteria asosiasi kesejarahan, integritas, kelangkaan, serta kualitas estetik. Asosiasi kesejarahan merupakan keterhubungan lanskap dengan kesejarahan. Integritas adalah kesatuan karakter, struktur, dan fungsi elemen dengan lingkungan sekitar. Kelangkaan adalah kekhasan yang dimiliki oleh objek tersebut yang mencirikan jarangnya ditemukan di objek wisata sejarah lain, sedangkan kualitas ekstetik adalah karakter dan struktur elemen yang mewakili suatu periode sejarah tertentu.

Pada kriteria asosiasi kesejarahan, seluruh objek wisata mendapatkan skor 5 (tinggi) dimana objek wisata dianggap memiliki hubungan kesejarahan yang kuat. Masa kesejarahan Kota Palembang dapat dibagi menjadi tiga periode, yakni periode Kerajaan Sriwijaya, periode Kesultanan, dan periode kemerdekaan. Pada periode kerajaan Sriwijaya, objek wisata seperti Taman Purbakala Kerajaan Sriwijaya hadir mepresentasikan peninggalan bersejarah periode tersebut. Sementara, Museum Sultan Mahmud Badaruddin II, Makan Ki Gede Ing Suro, Masjid Agung Sultan Mahdmud Badaruddin II, Bukit Siguntang, dan Museum Balaputra Dewa merupakan objek wisata yang menggambarkan sejarah di masa kesultanan. Sedangkan, objek wisata Monumen Perjuangan Rakyat (Monpera) dan Jembatan Ampera merupakan destinasi wisata yang menyimpan sejarah perjuangan kemerdekaan Indonesia. Keseluruh objek wisata yang diteliti menyimpan historis Kota Palembang di masing-masing periodenya. Fungsi kota Palembang sebagai Kota Budaya dan Kota Tertua di Indonesia (13 abad) yang menyimpan banyak 
peninggalan sejarah dan budaya diharapkan menjadi gateway city di dalam perjalanan kepariwisataan budaya Indonesia.

Dari kriteria kelangkaan, ketigabelas objek wisata sejarah di Kota Palembang mendapatkan skor tinggi. Hal ini dapat diartikan bahwa karakter dan struktur elemen yang ada di objek wisata tersebut bersifat khas dan jarang dijumpai di tempat lain serta memiliki nilai sejarah. Cikal bakal kota Palembang secara historis kultural, sosial ekonomi dan fisik tidak bisa dipisahkan dari keberadaan sungai Musi dan sebagai kota tertua di Indonesia, kota Palembang tentu memiliki dan menyimpan sejumlah kekayaan dan khasanah lansekap artefak budaya dan sejarah, utamanya dalam keterkaitannya dengan eksistensi Sungai Musi yang membelah kota ini (Subadyo,2012). Karakter dan fungsi Sungai Musi yang tidak hanya sebagai sumber air masyarakat Kota Palembang, tapi juga sebagai pembentuk kota Palembang baik secara kultural, fisik maupun sosio ekonomi inilah yang jarang dijumpai di daerah lain di Indonesia. Selain itu, bekas peninggalan sejarah dari masa Kerajaan Sriwijaya hingga masa kemerdekaan pun memiliki nilai historis yang tinggi.

Dari keseluruhan objek wisata yang diteliti, tiga diantaranya yakni Kawah Tengkurap, Makam Ki Gede Ing Suro, dan Kampung Assegaf mendapatkan nilai sedang pada kriteria kualitas estetika, sedangkan objek wisata lain mendapatkan nilai tinggi. Kualitas estetika dinilai tinggi apabila karakter dan struktur elemen memiliki nilai estetika atau gaya arsitektur masa lalu pada hampir semua bagian, termasuk detail ornament nya.

PadaobjekwisataKawah Tengkurap, Makam Ki Gede Ing Suro, dan Kampung Assegaf dinilai karakter dan struktur elemen pada objek wisata masih memiliki nilai estetika atau gaya arsitektur yang dapat menunjukkan kekhasannya pada masa lalu. Kondisi objek wisata Makam Ki Gede Ing Suro semakin hari semakin mengkhawatirkan karena tidak terurus dengan baik. Kondisi makam yang tidak terawat dan kondisi fasilitas pendukung wisata yang tidak berfungsi dengan menyebabkan objek wisata ini sepi pengunjung. Perkampungan Assegaf pun dinilai memiliki karakter dan struktur elemen yang menunjukkan kekhasannya di masa lampau seperti adanya pabrik es Alwi Assegaf serta perumahannya. Namun, kampung Assegaf tidak menunjukkan kekhasan masa lampau di semua bagian rumah hingga detail ornamen.

C. Kemudahan Aksesibilitas

Terdapat empat criteria untuk mengukur kemudahan aksesibilitas yaitu kemudahan akses, kapasitas, dan kejelasan. Kemudahan akses ini berdasarkan tingkat kemudahan serta tingkat keamanan dalam menjangkau lokasi objek wisata. Kapasitas ini menilai 
kemampuan objek wisata dalam menampung kendaraan pengunjung di lokasi objek wisata. Kejelasan akses berdasarkan tingkat kemudahan dalam menemukan petunjuk dalam perjalanan menuju objek wisata sejarah.

Seluruh objek wisata sejarah di Kota Palembang termasuk dalam kategori mudah untuk dikunjungi (skor 5). Wisatawan tidak memerlukan ijin khusus apabila ingin berkunjung di objek wisata sejarah Kota Palembang. Selain itu, objek wisata mudah dijangkau serta tidak ada resiko apabila dikunjungi banyak pengunjung. Namun, yang berbeda adalah dari sisi kriteria kapasitas objek wisata. Kriteria kapasitas wisata dinilai berdasarkan aksesibilitas lokasi wisata. Meskipun tergolong mudah untuk dikunjungi karena tersedia akses jalan, namun tidak semua objek wisata sejarah yang dilalui oleh angkutan umum. Hal ini tentu menyulitkan wisatawan yang memilih berkendara dengan transportasi publik.

Kapasitas objek wisata juga dapat dinilai dari lahan parkir yang tersedia. Beberapa objek wisata sejarah di Kota Palembang berada di tengah kota namun tidak memiliki fasilitas parkir yang memadai. Sebagai contoh objek wisata Monumen Perjuangan Rakyat, berlokasi di pusat kota dan dilewati oleh angkutan umum menyebabkan objek wisata ini potensial dikunjungi oleh wisatawan. Namun, hal ini tidak diiringi oleh fasilitas parkir yang memadai. Parkir motor dan mobil bagi pengunjung Monumen Perjuangan Rakyat ini menggunakan sistem parkir on street dengan kapasitas $<50$ kendaraan.

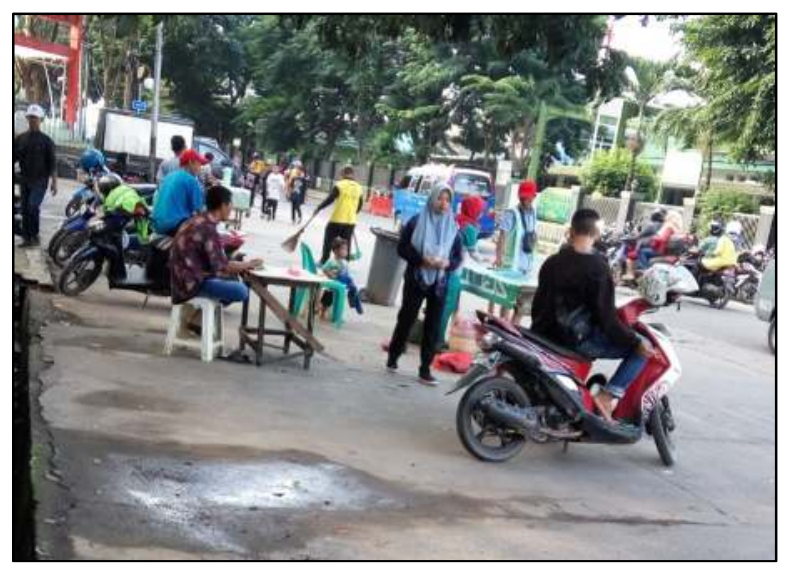

Gambar 2.Lahan Parkir bagi

Pengunjung Monumen Perjuangan Rakyat

Sumber: Hasil survei, 2018

Halini berbeda dengan objek wisata Masjid Agung Sultan Mahmud Badaruddin II. Terdapat halaman parkir yang luas untuk menampung kendaraan pengunjung. Lahan parkir di objek wisata ini cukup luas dan dibedakan antara parkir motor dan parkir 
mobil/bus. Namun sayangnya, untuk sebagian lahan parkir motor masih ada yang berupa tanah atau belum berupa pavingblock seluruhnya. Selain itu, tidak ada petugas parkir yang berada di sekitar lokasi parkir motor, sehingga motor-motor tersebut tidak tertata dengan rapi.
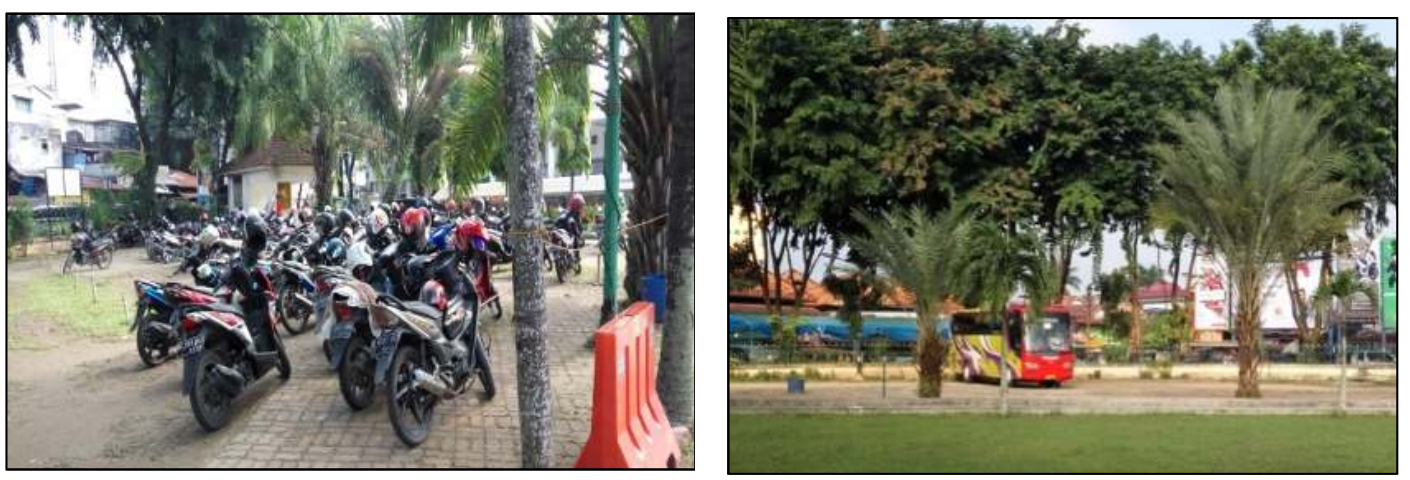

Gambar 3.Lahan Parkir di Masjid Agung Sultan Mahmud Badaruddin II Sumber: Hasil Survei, 2018

\section{KESIMPULAN DAN SARAN}

\section{Kesimpulan}

Kesimpulan yang dapat diambil dari hasil pembahasan penelitian mengenai kajian Potensi Objek Wisata Sejarah Berdasarkan Kelayakan Lanskap Sejarah di Kota Palembang adalah hasil skoring evaluasi nilai kelayakan objek wisata sejarah di Kota Palembang didapatkan hasil Kawah Tengkurap dan Kampung Kapitan termasuk dalam kategori rendah. Museum Sultan Mahmud Badaruddin II, Makam Ki Gede Ing Suro, dan Kampung Assegaf termasuk dalam kategori sedang. Sedangkan, objek wisata yang termasuk dalam kategori tinggi yakni Benteng Kuto Besak, Kampung Al Munawar, Taman Purbakala Kerjaan Sriwijaya, Bukit Siguntang, Museum Balaputra Dewa, dan Jembatan Ampera.

\section{Saran}

Berdasarkan kesimpulan di atas, maka saran yang terdapat beberapa rekomendasi untuk pengembangan wisata sejarah Kota Palembang ke depannya yaitu:

a. Perlu adanya perencanaan di tiap objek wisata yang termasuk dalam kategori rendah, baik itu dari sisi atraksi, fasilitas wisata, serta aksesibilitas. Dengan semakin beragam atraksi wisata yang ditawarkan, maka akan menarik wisatawan untuk mengunjungi objek wisata sejarah tersebut.

b. Pemerintah Kota Palembang sebagai stakeholder membuat perencanaan pariwisata secara komprehensif dengan melakukan sinkronisasi dengan tata 
ruang agar sektor pariwisata khususnya wisata sejarah memiliki dampak positif jangka panjang tidak hanya di aspek ekonomi tetapi juga lingkungan

c. Sosialisasi kepada masyarakat untuk ikut aktif dalam pelestarian kawasan wisata sejarah di Kota Palembang.

d. Adanya perencanaan rute wisata sejarah agar kunjungan wisatawan di objek wisata sejarah tidak hanya terkonsentrasi di beberapa objek saja.

\section{DAFTAR PUSTAKA}

Agustina, Kiptya Ayu. (2011). Pengembangan Kawasan Wisata Budaya Kota Surabaya. Skripsi. Surabaya: Institut Teknologi Sepuluh Nopember

Anonim. (2010). Undang-Undang No 11 Tahun 2010 tentang Cagar Budaya, Indonesia.

Ernawi. (2012). Kota Pusaka Langkah Indonesia Membuka Mata Dunia. Jakarta.

Goodchild P.H. (1990). Some Principal For Conservation of Historic Landscape. [Draft Document for Discussion Purpose]. Canada: Icomos (UK) Historic Gardens and Landscape Comittee. P 43-48

Harris CW dan Dinnes. N.T. (1988). Time Saver Standard For Landscape Architecture : Design And Construction Data. NY (US) : McGraw-Hill Co, Inc.

Maryam, Selvia. (2011). Pendekatan SWOT dalam Pengembangan Objek Wisata Kampoeng Djowo Sekatul Kabupaten Kendal. Skripsi. Semarang: UniversitasDiponegoro.

Mc. Intosh. (1995). Tourism Principles, Practices, Philosophies

Razak, A., dan Suprihardjo, R. (2013). Pengembangan Kawasan Pariwisata Terpadu di Kepulauan Seribu. Jurnal Teknik ITS, 2(1), C14-C19.

Son Sakira. (2013). Sejarah Jembatan Ampera Palembang. http://sonsakira.blogspot.com (diakes 26 Juni 2018)

Subadyo, I. H. T. (2012). Optimasi Potensi Artefak Budaya Pada Koridor Sungai MusiUntukPengembanganWisataSejarah di Kota Palembang. Journal of Architecture and Wetland Environment Studies, 1(1), 1-6.

Suwantoro, Gamal. (1997). Dasar-dasar Pariwisata. Yogyakarta: ANDI

Suyatmin. (2014). Model Pengelolaan Kawasan Cagar Budaya Berbasis Kearifan Lokal untuk Memacu Daya Terik Wisata Budaya-Sejarah :Kasus di Kawasan Kota Lama Semarang, Jawa Tengah. Surakarta: Universitas Muhamadiyah Surakarta. 
Jurnal Planologi Vol. 15, No. 2, Oktober 2018

Available : http://jurnal.unissula.ac.id/index.php/psa

Inskeep, E. (1991). Tourism Planning: an Integrated and Sustainable Development Approach. Van Nostrand Reinhold.

UNESCO (2009). Pariwisata Pusaka : Masa Depan bagi Kita, Alam dan Warisan Budaya Bersama. Jakarta.

Walker, L. A., dan Brooks, D. (1996). The Tourism Action Society in the Kootenays Stepby-Step Guide to Heritage Tourism Development in the Kootenay-Boundary. USA: Mcgrill.

Wirawan F.N. (2014). Pengembangan Jalur Wisata Sebagai Penunjang Wisata Sejarah Kota Bogor. Skripsi. Bogor : Institut Pertanian Bogor. 